\title{
Desempenho de populações de milho para produção de grãos e consumo in natura no Estado de Tocantins ${ }^{1}$
}

\author{
Performance of corn populations for grain yield and in natura consumption in \\ Tocantins State
}

\author{
Leandro Lopes Cancellier ${ }^{2 *}$, Flávio Sérgio Afférri, Onésimo Souza Cruz ${ }^{3}$, Joênes Mucci Peluzio e Aurélio Vaz \\ de Melo $^{3}$
}

\begin{abstract}
Resumo - A disponibilidade de cultivares destinadas à produção de milho verde é muito escassa, havendo necessidade de se desenvolverem novos híbridos apropriados para esse segmento. O objetivo deste trabalho foi avaliar o desempenho de genótipos de milho visando à produção de grãos e o potencial de consumo in natura no Sul do Estado do Tocantins. Os tratamentos foram constituídos de 158 populações e duas cultivares comerciais como testemunhas. O delineamento experimental utilizado foi blocos casualizados com quatro repetições, sendo avaliados: comprimento de espiga, diâmetro de espiga, formato da espiga, alinhamento de fileiras, cor da coroa do grão, tipo de grão, peso de 100 sementes e produtividade de grãos. Houve diferenciação dos genótipos para todas as características e para todas as variáveis há genótipos com características desejáveis visando ao mercado de consumo in natura. De acordo com os resultados, os genótipos 01-5; 02-1; 02-2; 02-3; 02-4; 10-5; 25-1; 32-1 e 34-4 são os que reúnem o conjunto de características mais favoráveis para o desenvolvimento de genótipos comerciais voltados para o consumo in natura, e os genótipos do programa de melhoramento de Milho da Universidade Federal do Tocantins possuem potencial produtivo e podem ser utilizados para o desenvolvimento de cultivares voltados para uso nas condições edafoclimáticas do Estado do Tocantins. As populações avaliadas possuem variabilidade para ser explorada nos programas de melhoramento visando a diferentes aptidões comerciais.
\end{abstract}

Palavras-chave - Zea mays L. Milho verde. Melhoramento genético. Populações.

\begin{abstract}
The cultivars availability for green corn production is very scarce, so there is need to develop new hybrid appropriate for that segment. This work aimed to evaluate performance of corn genotypes to grain yield and potential of in natura consumption in south of Tocantins State. The experiment was planted in Gurupi-TO, on April 25, 2009. The treatments were 158 populations and two cultivars as witness. The experimental design was randomized block with four replications, were evaluated: ear length, ear diameter, ear format, alignment of rows, crown color of grain, grain type, 100 seeds weight and grain yield. There was a differentiation of genotypes for all characteristics and for all variables there are genotypes with desirable characteristics on market for in natura consumption. Thus, conclude that the genotypes $01-5 ; 02-1 ; 02-2 ; 02-3 ; 02-4 ; 10-5 ; 25-1 ; 32-1$ and $34-4$ have the aggregate of favorable characteristics for development of commercial genotypes for in natura consumption, moreover the corn genotypes of UFT maize breeding program have yield potential and can be used to cultivars development for use in Tocantins conditions. The evaluated populations have variability for exploration in breeding programs aiming different commercials uses.
\end{abstract}

Key words - Zea mays L. Green corn. Genetic breeding. Population.

\footnotetext{
*Autor para correspondência

${ }^{1}$ Recebido para publicação em 15/04/2010; aprovado em 04/04/2011

Parte da dissertação de Mestrado do primeiro autor, apresentada ao Programa de Pós-Graduação em Produção Vegetal da UFT

${ }^{2}$ Programa de Pós-Graduação em Agronomia/Fitotecnia/Departamento de agricultura, UFLA, Lavras-MG, Brasil, 37.200-000, leandrocancellier@ gmail.com

${ }_{3}^{3}$ Universidade Federal do Tocantins, Campus de Gurupi, Caixa Postal 66, 77.402-970, Gurupi-TO, Brasil, flavio@uft.edu.br, onesimo89@hotmail.com, joenesp@uft.edu.br, vazdemelo@uft.edu.br
} 


\section{Introdução}

O milho (Zea mays L.) é largamente cultivado e consumido em todos os continentes, com produção de cerca de 600 milhões de toneladas, inferior apenas às do trigo e do arroz. Os Estados Unidos, a China e o Brasil são os maiores produtores mundiais (OLIVEIRA et al., 2009). A produtividade brasileira tem crescido sistematicamente, passando de $1.665 \mathrm{~kg} \mathrm{ha}^{-1}$, em 1980, para $3.600 \mathrm{~kg} \mathrm{ha}^{-1}$, em 2009 (CONAB, 2010).

No milho verde, o grão é a parte consumida diretamente e utilizada na elaboração de pratos tradicionais na culinária. O consumidor dá preferência a espigas de maior comprimento e, por esse motivo, esse atributo é considerado na comercialização do milho para consumo in natura ou para a indústria de enlatados (PINHO et al., 2008).

O consumo de milho verde sempre foi uma tradição no Brasil, sendo comum à comercialização na forma de espigas, grãos enlatados e seus subprodutos (pamonha, curau e suco) (RODRIGUES et al., 2009).

Adisponibilidadedecultivares destinadas à produção de milho verde é muito escassa, havendo a necessidade de se desenvolverem novos híbridos apropriados para esse segmento. Em 2007, somente nove cultivares foram recomendadas para a produção de milho verde, dentre 275 cultivares de milho disponíveis para a comercialização no Brasil (CRUZ; PEREIRA FILHO, 2007).

A escolha do germoplasma é parte fundamental e decisiva em qualquer programa de melhoramento de plantas para o desenvolvimento de variedades, para utilização em híbridos ou para estudos básicos, podendo inclusive influir significativamente no sucesso ou no fracasso da seleção (ARAUJO; NASS, 2002).

De maneira geral, as populações podem ser menos produtivas que as cultivares comerciais, entretanto essas populações são importantes por constituírem fonte de variabilidade genética que podem ser exploradas na busca por genes tolerantes e/ou resistentes aos fatores bióticos e abióticos (ARAUJO; NASS, 2002) e também para explorar nichos de mercado específicos como o desenvolvimento de genótipos de milho verde para consumo in natura, assim como genótipos adaptados as condições adversas que ocorre na região norte, sendo que não há programas de melhoramento privado visando atender essa região (CANCELLIER et al., 2011).

A avaliação de cultivares quanto ao rendimento de milho verde é especialmente interessante, pois agrega valor ao produto e melhora a renda dos produtores, principalmente em pequenas propriedades (CÂMARA, 2007). Porém, há escassez de informações no Brasil sobre a avaliação e obtenção de cultivares destinadas à produção de milho verde (RODRIGUES et al., 2009).
A aparência do produto destinado à alimentação humana é de fundamental importância para a sua comercialização e exerce grande influência na aceitação do produto (ALBUQUERQUE et al., 2008). Por isso, utilizar a avaliação de características visuais é importante em programas de melhoramento, nas etapas de seleção de genótipos, proporcionando ganho de tempo, com baixo custo e rápida mensuração e gerando cultivares com características visuais favoráveis à comercialização e aliada a produtividades satisfatórias (DURÃES et al., 2004).

O estudo da aceitação do produto pelo consumidor é parte crucial no processo de desenvolvimento emelhoramento, cabendo ao melhorista utilizar tal recurso a fim de investigar a potencialidade do novo produto advindo do melhoramento genético (OLIVEIRA JÚNIOR et al., 2006). Ressalta-se, ainda, que as cultivares para o consumo de milho verde devem apresentar endurecimento lento do grão, espigas grandes e com bom empalhamento, sabugo branco e grãos amarelos do tipo dentado e com alinhamento retilíneo.

O objetivo deste trabalho foi avaliar o desempenho de populações de milho visandoà produção de grãos e ao potencial de consumo in natura no Sul do Estado do Tocantins.

\section{Materiais e métodos}

O experimento foi instalado em área experimental no município de Gurupi-TO, no dia 25 de abril de 2009. Os tratamentos foram constituídos de 160 genótipos, sendo 158 populações obtidas do Programa de Melhoramento de Milho da Universidade Federal do Tocantins (UFT) e duas cultivares comerciais como testemunha (BR 106 e AS1522).

O delineamento experimental utilizado foi blocos casualizados com quatro repetições. Para a instalação do experimento, foi utilizado o sistema de preparo de solo tipo convencional, com uma gradagem e sulcos com o espaçamento de $0,9 \mathrm{~m}$ entre linha. As parcelas constituíram-se de uma linha de quatro metros lineares.

A semeadura e a adubação no sulco foram feitas manualmente. A adubação de plantio foi realizada utilizando-se $400 \mathrm{~kg} \mathrm{ha}^{-1}$ de 5-25-15 + 0,5\% Zn de NPK. Plantou-se o milho na parcela a fim de obter $55 \mathrm{mil}$ plantas ha ${ }^{-1}$. A adubação de cobertura foi realizada no dia 23/05/2009 com $100 \mathrm{~kg} \mathrm{ha}^{-1}$ de N. Os tratos culturais como o controle da competição de plantas daninhas, pragas, doenças e irrigação suplementar foram realizados de acordo com as recomendações técnicas da cultura (FANCELLI; DOURADO NETO, 2000).

As seguintes características foram avaliadas: comprimento de espiga - comprimento, em milímetros, da base ao ápice da espiga; diâmetro de espiga - diâmetro 
da parte mediana da espiga, em milímetros; formato da espiga - foram consideradas três notas: 1 para formato de espiga cônica, 2 para formato cônica/cilíndrica e 3 para formato cilíndrico; alinhamento de fileiras - considerando-se quatro notas: 1 para alinhamento reto, 2 para alinhamento levemente curvado, 3 para alinhamento em espiral e 4 para alinhamento irregular; cor da coroa do grão, com oito notas: 1 para cor branca, 2 para cor branca amarelada, 3 para cor amarela, 4 para cor amarela alaranjada, 5 para cor alaranjada, 6 para cor vermelha alaranjada, 7 para cor vermelha e 8 para cor vermelha escura; tipo de grão, com quatro notas: 1 para duro, 2 para semi-duro, 3 para semi-dentado e 4 para dentado; peso de 100 sementes - peso, em gramas, de amostras de 100 grãos, corrigido para $13 \%$ de umidade; e produtividade de grãos - que foi obtida pela pesagem dos grãos debulhados, em $\mathrm{kg}_{\text {parcela }}{ }^{-1}$, corrigido para $13 \%$ de umidade e posteriormente convertidos os valores para $\mathrm{kg} \mathrm{ha}^{-1}$.

Para a análise dos dados foi realizada a análise de variância e aplicado o teste de agrupamento de Scott e Knott quando ocorreram diferenças significativas entre as variáveis, pelo teste $\mathrm{F}$.

\section{Resultados e discussões}

Houve diferença significativa pelo teste $\mathrm{F}$, segundo a análise de variância (TAB. 1), para todas as características avaliadas, sendo que apenas a característica alinhamento de fileiras com diferença a $5 \%$ de probabilidade, e as demais com diferença a $1 \%$ de probabilidade, indicaram que as características avaliadas são adequadas para discriminar os genótipos.

Com relação ao diâmetro de espiga (TAB. 2), houve a formação de dois grupos estatísticos pelo teste Scott e Knott, com 81 genótipos no grupo de maiores médias e 79 no grupo de menores médias, com as médias dos diâmetros de espiga do grupo superior variando de 45,1 a 52,6 mm e as do grupo inferior variando de 37,5 a $45 \mathrm{~mm}$. O baixo coeficiente de variação (C.V.) indica uma boa precisão na avaliação desta característica (7,8\%). As cultivares BR106 e AS1522 se encontram no grupo dos genótipos de maiores médias de diâmetro de espiga, podendo-se inferir assim que os genótipos do grupo de maiores médias podem ser utilizados em programas de melhoramento para produção de novas cultivares, considerando esta característica.

Oliveira Júnior et al. (2006), avaliando seis genótipos de milho para consumo in natura, apresentaram média de $44 \mathrm{~mm}$ para o diâmetro de espigas, resultado próximo ao encontrado no presente trabalho, com $45 \mathrm{~mm}$ de diâmetro.

Para Moraes (2010) e Santos et al. (2005), o diâmetro de espiga recomendado para o milho verde é 30 $\mathrm{mm}$ ou superior. Considerando-se que no presente trabalho o genótipo 17-2 apresentou o menor diâmetro de espiga (37,7 mm), os genótipos estudados apresentam diâmetro de espigas adequado para o desenvolvimento de genótipos comerciais voltados para tal fim.

Com relação à variável comprimento de espiga (TAB. 2) os genótipos foram diferenciados em dois grupos, sendo 76 no grupo superior e 84 genótipos no grupo inferior. A média desta característica foi $153,9 \mathrm{~mm}$ e o coeficiente de variação foi de $12,9 \%$. A cultivar testemunha AS1522 se encontra no grupo dos genótipos inferiores e a cultivar BR106 no grupo superior. Mesmo a cultivar AS1522 sendo um híbrido comercial, seu comprimento de espiga foi de $146,8 \mathrm{~mm}, 5 \%$ inferior a média geral do experimento.

Considerando-se que o comprimento de espiga é uma característica altamente correlacionada com a produtividade (SANTOS et al., 2005), os genótipos do grupo de maiores médias apresentam-se potencialmente favoráveis para desenvolver rendimentos satisfatórios. Albuquerque et al. (2008) observaram correlação positiva entre a altura de plantas e o comprimento médio das espigas, indicando que a seleção para plantas altas implicará em espigas maiores e mais pesadas.

Pereira Filho e Cruz (2002) afirmam que o comprimento de espiga ideal para atender tanto os interesses da indústria de envasamento quanto à produção

Tabela 1 - Resumo da análise de variância de comprimento de espiga (Comp), diâmetro de espiga (Desp), formato de espiga (Form), alinhamento de fileiras (Alin), cor da espiga (Cor), tipo de grão (Tipo), peso de 100 sementes (P100S) e produtividade (Prod) de 160 genótipos de milho em Gurupi - TO, 2009

\begin{tabular}{cccccccccc}
\hline \multirow{2}{*}{ F.V. } & GL & \multicolumn{1}{c}{ Quadrado médio } & \multicolumn{1}{c}{ P100S } & Prod \\
\cline { 2 - 10 } & & Comp & Desp & Form & Alin & Cor & Tipo & P100 \\
\hline Genótipos & 159 & $602,6^{* *}$ & $35,9^{* *}$ & $0,41^{* *}$ & $0,59^{*}$ & $0,65^{* *}$ & $0,59^{* *}$ & $44,6^{* *}$ & $1825676^{* *}$ \\
Blocos & 3 & 876,3 & 188,4 & 5,31 & 3,19 & 3,59 & 0,4 & 84,4 & 6101603 \\
Resíduo & 477 & 398,3 & 12,3 & 0,25 & 0,44 & 0,21 & 0,3 & 18,9 & 928828 \\
\hline C.V. (\%) & - & 12,9 & 7,8 & 21,7 & 32,7 & 12,7 & 37,0 & 14,8 & 20,9 \\
\hline *e** significativo ao nível de 5 e 1\%, respectivamente pelo teste F & & & & &
\end{tabular}


Tabela 2 - Médias de diâmetro (Desp) e comprimento de espiga (Comp) em mm de 160 genótipos de milho em Gurupi - TO, 2009

\begin{tabular}{|c|c|c|c|c|c|c|c|c|}
\hline Genótipos & Desp & Comp & Genótipos & Desp & Comp & Genótipos & Desp & Comp \\
\hline $11-2$ & $50,2 \mathrm{a}$ & $183,7 \mathrm{a}$ & $22-3$ & $43,0 \mathrm{~b}$ & $158,6 \mathrm{a}$ & $27-1$ & $45,5 \mathrm{a}$ & $148,6 \mathrm{~b}$ \\
\hline $01-4$ & $46,6 \mathrm{a}$ & $181,3 \mathrm{a}$ & $18-6$ & $42,5 \mathrm{~b}$ & $158,5 \mathrm{a}$ & $20-1$ & $44,1 \mathrm{~b}$ & $148,3 \mathrm{~b}$ \\
\hline $19-3$ & $45,6 \mathrm{a}$ & $180,7 \mathrm{a}$ & $13-1$ & $41,2 \mathrm{~b}$ & $158,5 \mathrm{a}$ & $27-2$ & $47,1 \mathrm{a}$ & $147,8 \mathrm{~b}$ \\
\hline $25-5$ & $47,1 \mathrm{a}$ & $179,0 \mathrm{a}$ & $26-2$ & $45,8 \mathrm{a}$ & $158,1 \mathrm{a}$ & $24-3$ & $41,6 \mathrm{~b}$ & $147,7 \mathrm{~b}$ \\
\hline $19-5$ & $44,6 \mathrm{~b}$ & $179,0 \mathrm{a}$ & $23-1$ & $43,2 \mathrm{~b}$ & $158,0 \mathrm{a}$ & $29-1$ & $48,6 \mathrm{a}$ & $147,3 \mathrm{~b}$ \\
\hline $14-2$ & $42,6 \mathrm{~b}$ & $178,6 \mathrm{a}$ & $19-4$ & $43,3 \mathrm{~b}$ & $157,5 \mathrm{a}$ & $03-5$ & $42,5 \mathrm{~b}$ & $147,0 \mathrm{~b}$ \\
\hline $03-2$ & $41,3 \mathrm{~b}$ & $177,8 \mathrm{a}$ & $30-3$ & $44,5 \mathrm{~b}$ & $157,5 \mathrm{a}$ & AS1522 & $45,3 \mathrm{a}$ & $146,8 \mathrm{~b}$ \\
\hline $02-3$ & $45,8 \mathrm{a}$ & $175,8 \mathrm{a}$ & $21-1$ & $40,0 \mathrm{~b}$ & $157,5 \mathrm{a}$ & $32-2$ & $45,2 \mathrm{a}$ & $146,8 \mathrm{~b}$ \\
\hline $34-4$ & $47,6 \mathrm{a}$ & $174,3 \mathrm{a}$ & $32-5$ & $48,6 \mathrm{a}$ & $157,2 \mathrm{a}$ & $34-3$ & $42,1 \mathrm{~b}$ & $146,7 \mathrm{~b}$ \\
\hline $22-1$ & $43,7 \mathrm{~b}$ & $174,3 \mathrm{a}$ & $02-4$ & $40,5 \mathrm{~b}$ & $157,1 \mathrm{a}$ & $30-2$ & $45,5 \mathrm{a}$ & $146,6 \mathrm{~b}$ \\
\hline $19-6$ & $44,0 \mathrm{~b}$ & $172,5 \mathrm{a}$ & $25-1$ & $49,6 \mathrm{a}$ & $156,8 \mathrm{a}$ & $21-3$ & $44,6 \mathrm{~b}$ & $146,6 \mathrm{~b}$ \\
\hline $33-2$ & $41,8 \mathrm{~b}$ & $171,8 \mathrm{a}$ & $26-3$ & $43,1 \mathrm{~b}$ & $156,7 \mathrm{a}$ & $28-2$ & $45,5 \mathrm{a}$ & $146,5 \mathrm{~b}$ \\
\hline $34-2$ & $45,7 \mathrm{a}$ & $169,3 \mathrm{a}$ & $36-1$ & $46,8 \mathrm{a}$ & $156,6 \mathrm{a}$ & $20-6$ & $45,3 \mathrm{a}$ & $146,0 \mathrm{~b}$ \\
\hline $10-1$ & $45,7 \mathrm{a}$ & $169,3 \mathrm{a}$ & $33-3$ & $37,5 \mathrm{~b}$ & $156,6 \mathrm{a}$ & $35-2$ & $45,8 \mathrm{a}$ & $145,3 \mathrm{~b}$ \\
\hline $03-3$ & $42,2 \mathrm{~b}$ & $169,2 \mathrm{a}$ & $03-6$ & $41,3 \mathrm{~b}$ & $156,5 \mathrm{a}$ & 04-1 & $43,1 \mathrm{~b}$ & $144,7 \mathrm{~b}$ \\
\hline $01-3$ & $46,6 \mathrm{a}$ & $169,1 \mathrm{a}$ & $02-6$ & $43,1 \mathrm{~b}$ & $156,3 \mathrm{a}$ & $32-6$ & $48,5 \mathrm{a}$ & 144,6 b \\
\hline $15-3$ & $42,0 \mathrm{~b}$ & $168,5 \mathrm{a}$ & $22-6$ & $48,1 \mathrm{a}$ & $156,1 \mathrm{a}$ & $28-1$ & $48,3 \mathrm{a}$ & $144,1 \mathrm{~b}$ \\
\hline $02-1$ & $47,7 \mathrm{a}$ & $168,3 \mathrm{a}$ & $16-6$ & $42,5 \mathrm{~b}$ & $156,1 \mathrm{a}$ & $23-2$ & $45,1 \mathrm{a}$ & $144,0 \mathrm{~b}$ \\
\hline $26-1$ & $46,5 \mathrm{a}$ & $167,7 \mathrm{a}$ & $18-5$ & $44,8 \mathrm{~b}$ & $156,1 \mathrm{a}$ & $06-3$ & $43,5 \mathrm{~b}$ & $143,8 \mathrm{~b}$ \\
\hline $15-6$ & $43,1 \mathrm{~b}$ & $167,5 \mathrm{a}$ & $18-4$ & $43,5 \mathrm{~b}$ & $155,2 \mathrm{a}$ & $28-4$ & $47,2 \mathrm{a}$ & $143,3 \mathrm{~b}$ \\
\hline $15-1$ & $47,0 \mathrm{a}$ & $167,5 \mathrm{a}$ & $08-3$ & $43,5 \mathrm{~b}$ & $155,2 \mathrm{a}$ & $34-5$ & $47,2 \mathrm{a}$ & $143,1 \mathrm{~b}$ \\
\hline $02-2$ & $46,1 \mathrm{a}$ & $167,3 \mathrm{a}$ & $20-4$ & $44,5 \mathrm{~b}$ & $155,1 \mathrm{a}$ & $07-1$ & $43,1 \mathrm{~b}$ & $142,5 \mathrm{~b}$ \\
\hline $30-1$ & $46,5 \mathrm{a}$ & $167,2 \mathrm{a}$ & $28-3$ & $48,7 \mathrm{a}$ & $154,3 \mathrm{~b}$ & 01-1 & $44,8 \mathrm{~b}$ & $142,2 \mathrm{~b}$ \\
\hline $21-2$ & $42,2 \mathrm{~b}$ & $167,0 \mathrm{a}$ & $16-5$ & $46,8 \mathrm{a}$ & $154,1 \mathrm{~b}$ & $30-4$ & $44,8 \mathrm{~b}$ & $141,8 \mathrm{~b}$ \\
\hline $10-2$ & $46,6 \mathrm{a}$ & $167,0 \mathrm{a}$ & $35-6$ & $49,2 \mathrm{a}$ & $154,0 \mathrm{~b}$ & $25-3$ & $43,7 \mathrm{~b}$ & $141,6 \mathrm{~b}$ \\
\hline BR106 & $45,5 \mathrm{a}$ & $166,8 \mathrm{a}$ & $05-1$ & $47,5 \mathrm{a}$ & $154,0 \mathrm{~b}$ & $08-1$ & $43,8 \mathrm{~b}$ & $141,6 \mathrm{~b}$ \\
\hline $21-6$ & $45,3 \mathrm{a}$ & $166,2 \mathrm{a}$ & $16-4$ & $42,5 \mathrm{~b}$ & $153,6 \mathrm{~b}$ & $33-5$ & $41,8 \mathrm{~b}$ & $141,5 \mathrm{~b}$ \\
\hline $15-5$ & $42,5 \mathrm{~b}$ & $165,8 \mathrm{a}$ & $16-2$ & $49,6 \mathrm{a}$ & $153,6 \mathrm{~b}$ & $20-3$ & $46,5 \mathrm{a}$ & $141,3 \mathrm{~b}$ \\
\hline $12-6$ & $45,7 \mathrm{a}$ & $165,6 \mathrm{a}$ & $34-6$ & $47,2 \mathrm{a}$ & $153,5 \mathrm{~b}$ & $20-5$ & $45,5 \mathrm{a}$ & $141,1 \mathrm{~b}$ \\
\hline $12-4$ & $47,0 \mathrm{a}$ & $165,6 \mathrm{a}$ & $12-5$ & $51,2 \mathrm{a}$ & $153,5 \mathrm{~b}$ & $24-2$ & $42,7 \mathrm{~b}$ & $141,0 \mathrm{~b}$ \\
\hline $19-1$ & $42,2 \mathrm{~b}$ & $165,5 \mathrm{a}$ & $28-5$ & $47,8 \mathrm{a}$ & $153,3 \mathrm{~b}$ & $02-5$ & $45,0 \mathrm{~b}$ & $140,3 \mathrm{~b}$ \\
\hline $35-5$ & $48,7 \mathrm{a}$ & $165,1 \mathrm{a}$ & $27-3$ & $42,6 \mathrm{~b}$ & $153,3 \mathrm{~b}$ & $07-2$ & $47,0 \mathrm{a}$ & $140,0 \mathrm{~b}$ \\
\hline $09-3$ & $52,6 \mathrm{a}$ & $165,0 \mathrm{a}$ & $01-6$ & $45,0 \mathrm{~b}$ & $153,2 \mathrm{~b}$ & $01-2$ & $43,0 \mathrm{~b}$ & $140,0 \mathrm{~b}$ \\
\hline $01-5$ & $48,8 \mathrm{a}$ & $164,5 \mathrm{a}$ & $03-1$ & $43,1 \mathrm{~b}$ & $153,1 \mathrm{~b}$ & $31-3$ & $40,8 \mathrm{~b}$ & $139,3 \mathrm{~b}$ \\
\hline $21-5$ & $45,5 \mathrm{a}$ & $164,3 \mathrm{a}$ & $22-5$ & $43,3 \mathrm{~b}$ & $152,7 \mathrm{~b}$ & $28-6$ & $47,7 \mathrm{a}$ & $138,3 \mathrm{~b}$ \\
\hline $15-4$ & $40,5 \mathrm{~b}$ & $164,3 \mathrm{a}$ & $18-2$ & $41,1 \mathrm{~b}$ & $152,7 \mathrm{~b}$ & $17-1$ & $46,7 \mathrm{a}$ & $137,8 \mathrm{~b}$ \\
\hline $35-4$ & $47,8 \mathrm{a}$ & $163,5 \mathrm{a}$ & $25-4$ & $51,8 \mathrm{a}$ & $152,6 \mathrm{~b}$ & $32-3$ & $49,3 \mathrm{a}$ & $137,3 \mathrm{~b}$ \\
\hline $19-2$ & $42,7 \mathrm{~b}$ & $162,7 \mathrm{a}$ & $06-1$ & $44,6 \mathrm{~b}$ & $152,3 \mathrm{~b}$ & $27-5$ & $41,3 \mathrm{~b}$ & $137,2 \mathrm{~b}$ \\
\hline $35-3$ & $48,1 \mathrm{a}$ & $162,6 \mathrm{a}$ & $16-3$ & $46,2 \mathrm{a}$ & $152,2 \mathrm{~b}$ & $33-1$ & $41,5 \mathrm{~b}$ & $137,1 \mathrm{~b}$ \\
\hline $10-6$ & $43,7 \mathrm{~b}$ & $162,1 \mathrm{a}$ & $05-2$ & $48,5 \mathrm{a}$ & $152,1 \mathrm{~b}$ & $18-3$ & $39,1 \mathrm{~b}$ & $135,6 \mathrm{~b}$ \\
\hline $22-4$ & $45,3 \mathrm{a}$ & $162,0 \mathrm{a}$ & $05-3$ & $45,0 \mathrm{~b}$ & $152,0 \mathrm{~b}$ & $03-4$ & $42,1 \mathrm{~b}$ & $135,0 \mathrm{~b}$ \\
\hline
\end{tabular}


Continuação Tabela 2

\begin{tabular}{ccccccccc}
\hline $15-2$ & $41,0 \mathrm{~b}$ & $160,6 \mathrm{a}$ & $24-1$ & $43,3 \mathrm{~b}$ & $151,8 \mathrm{~b}$ & $16-1$ & $43,5 \mathrm{~b}$ & $135,0 \mathrm{~b}$ \\
$09-2$ & $49,5 \mathrm{a}$ & $160,3 \mathrm{a}$ & $22-2$ & $43,3 \mathrm{~b}$ & $151,2 \mathrm{~b}$ & $18-1$ & $41,3 \mathrm{~b}$ & $134,3 \mathrm{~b}$ \\
$11-1$ & $50,5 \mathrm{a}$ & $160,2 \mathrm{a}$ & $29-2$ & $46,1 \mathrm{a}$ & $151,1 \mathrm{~b}$ & $27-4$ & $39,5 \mathrm{~b}$ & $134,0 \mathrm{~b}$ \\
$10-4$ & $45,2 \mathrm{a}$ & $160,1 \mathrm{a}$ & $36-2$ & $44,7 \mathrm{~b}$ & $150,7 \mathrm{~b}$ & $30-5$ & $46,8 \mathrm{a}$ & $133,7 \mathrm{~b}$ \\
$08-2$ & $44,0 \mathrm{~b}$ & $160,0 \mathrm{a}$ & $35-1$ & $50,2 \mathrm{a}$ & $150,6 \mathrm{~b}$ & $30-6$ & $45,1 \mathrm{a}$ & $133,2 \mathrm{~b}$ \\
$12-1$ & $51,2 \mathrm{a}$ & $160,0 \mathrm{a}$ & $32-4$ & $51,1 \mathrm{a}$ & $150,6 \mathrm{~b}$ & $32-1$ & $47,3 \mathrm{a}$ & $130,5 \mathrm{~b}$ \\
$06-2$ & $44,8 \mathrm{~b}$ & $159,8 \mathrm{a}$ & $34-1$ & $46,0 \mathrm{a}$ & $150,2 \mathrm{~b}$ & $17-2$ & $37,7 \mathrm{~b}$ & $128,5 \mathrm{~b}$ \\
$21-4$ & $44,0 \mathrm{~b}$ & $159,7 \mathrm{a}$ & $25-2$ & $48,6 \mathrm{a}$ & $150,0 \mathrm{~b}$ & $07-3$ & $44,3 \mathrm{~b}$ & $127,6 \mathrm{~b}$ \\
$09-1$ & $49,3 \mathrm{a}$ & $159,6 \mathrm{a}$ & $12-2$ & $49,5 \mathrm{a}$ & $150,0 \mathrm{~b}$ & $25-6$ & $46,8 \mathrm{a}$ & $125,7 \mathrm{~b}$ \\
$11-3$ & $50,2 \mathrm{a}$ & $159,3 \mathrm{a}$ & $12-3$ & $49,6 \mathrm{a}$ & $149,8 \mathrm{~b}$ & $14-1$ & $39,7 \mathrm{~b}$ & $125,6 \mathrm{~b}$ \\
$20-2$ & $47,7 \mathrm{a}$ & $159,1 \mathrm{a}$ & $10-3$ & $44,7 \mathrm{~b}$ & $149,2 \mathrm{~b}$ & $33-4$ & $39,3 \mathrm{~b}$ & $124,6 \mathrm{~b}$ \\
$33-6$ & $42,6 \mathrm{~b}$ & $159,0 \mathrm{a}$ & $31-1$ & $40,6 \mathrm{~b}$ & $149,0 \mathrm{~b}$ & Média & 45,1 & 153,9 \\
$10-5$ & $46,7 \mathrm{a}$ & $158,7 \mathrm{a}$ & $31-2$ & $41,3 \mathrm{~b}$ & $148,8 \mathrm{~b}$ & C.V. $(\%)$ & 7,8 & 12,9 \\
\hline
\end{tabular}

Médias seguidas de mesma letra não diferem entre si a 5\% de significância pelo teste Scott e Knott

para o uso in natura situa-se próximo a $200 \mathrm{~mm}$. A variação do comprimento de espigas do grupo dos 76 genótipos superiores foi de 183,7 a $155,1 \mathrm{~mm}$, próximo ao ideal. Já Moraes (2010) e Santos et al. (2005) afirmam que o comprimento de espiga recomendado para milho verde é de $150 \mathrm{~mm}$ ou maior.

Segundo Santos et al. (2005), as características produção de espigas e comprimento da espiga apresentam altas correlações simples e parcial, mostrando que a seleção com base em comprimento de espiga tende a aumentar a produção de espigas. O comprimento de espiga também apresenta alta correlação com o diâmetro de espigas. Portanto, genótipos com comprimento de espigas ideal para a comercialização de espigas verdes tendem a apresentar o seu diâmetro também dentro do padrão.

Não houve diferenciação de grupos estatísticos para as notas de alinhamento de fileiras (TAB. 3), mesmo havendo diferença significativa pelo teste $\mathrm{F}$. Esta característica apresentou uma nota média 2 , o qual corresponderia a alinhamento de fileira levemente curvado, e um coeficiente de variação de $32,7 \%$. As notas variaram de 1,2 para o genótipo 03-3, o que caracteriza alinhamento de fileiras reto, e 3,5 para o genótipo 17-2, o que corresponde ao intermediário de alinhamento em espiral a irregular. Os cultivares testemunha, como o híbrido AS1522, apresentaram notas de alinhamento 1,8, com alinhamento próximo a levemente curvado, porém 55 genótipos obtiveram notas de alinhamento inferiores a este híbrido, correspondendo a alinhamento de fileiras retilíneo.

Santos et al. (2005) relatam a possibilidade de seleção indireta de espigas de maior comprimento, escolhendo-se espigas que apresentam alinhamento de fileiras retilíneo. Portanto, mesmo não havendo diferença significativa entre os genótipos, esta característica pode ser utilizada de forma indireta para selecionar genótipos com espigas maiores que são adequadas para o comércio do milho verde, já que são características correlacionadas.

Para a característica formato de espiga (TAB. 3) dois grupos foram formados pelo teste Scott e Knott, sendo 86 genótipos no grupo superior e 74 genótipos no grupo inferior. A nota média desta característica é 2,3, correspondendo a formato cônico/cilíndrico. O coeficiente de variação para formato de espiga é de 21,7\%. As notas do grupo superior variaram de 2,3 a 3,0, indicando que estes genótipos possuem espigas com formato cilíndrico a cilíndrico/cônico.

As cultivares comerciais AS1522 e BR106 apresentaram notas de formato 1,3 e 1,5 respectivamente, indicando formato cônico, o qual, segundo Pereira Filho e Cruz (2002), não é uma característica desejável para atender à indústria de envasamento e ao uso in natura. Pereira Filho e Cruz (2002) e Moraes (2010) citam ainda que o formato de espiga ideal para tal fim seria o formato cilíndrico.

Considerando tal característica, os genótipos do grupo superior possuem formato de espigas adequado para a comercialização de espigas de milho verde.

A cor da coroa dos grãos (TAB. 4) foi, pelo teste Scott e Knott, classificada em três grupos, sendo 32 genótipos no grupo de maiores médias, com notas variando de 4 a 5,3, que corresponde à cor amarelo alaranjado a alaranjado, com destaque para o tratamento 10-6 com nota 5,3 ou seja, cor alaranjada. $\mathrm{O}$ grupo de genótipos de menores médias apresenta-se com 70 genótipos, com notas variando de 2,6 a 3,5, e 58 genótipos no grupo de médias intermediárias, com notas variando de 3,6 a 3,8. O híbrido comercial AS1522 se encontra no grupo de menor média, com nota 3,1 correspondendo à cor amarela, e a variedade comercial BR106, no grupo intermediário, com nota 3,6. 
Tabela 3 - Médias de formato de espiga (Form) e alinhamento de fileiras (Alin) de 160 genótipos de milho em Gurupi - TO, 2009

\begin{tabular}{|c|c|c|c|c|c|c|c|c|}
\hline Genótipos & Alin & Form & Genótipos & Alin & Form & Genótipos & Alin & Form \\
\hline $24-3$ & $1,8 \mathrm{a}$ & $3,0 \mathrm{a}$ & $19-1$ & $1,8 \mathrm{a}$ & $2,5 \mathrm{a}$ & $35-4$ & $2,3 \mathrm{a}$ & $2,1 \mathrm{~b}$ \\
\hline $02-3$ & $1,8 \mathrm{a}$ & $3,0 \mathrm{a}$ & $17-1$ & $2,2 \mathrm{a}$ & $2,5 \mathrm{a}$ & $34-3$ & $1,8 \mathrm{a}$ & $2,1 \mathrm{~b}$ \\
\hline $14-1$ & $2,2 \mathrm{a}$ & $3,0 \mathrm{a}$ & $13-1$ & $1,6 \mathrm{a}$ & $2,5 \mathrm{a}$ & $33-4$ & $2,2 \mathrm{a}$ & $2,1 \mathrm{~b}$ \\
\hline $16-6$ & $2,1 \mathrm{a}$ & $2,8 \mathrm{a}$ & $36-2$ & $1,7 \mathrm{a}$ & $2,3 \mathrm{a}$ & $20-6$ & $2,5 \mathrm{a}$ & $2,1 \mathrm{~b}$ \\
\hline $20-3$ & $1,8 \mathrm{a}$ & $2,8 \mathrm{a}$ & $36-1$ & $1,5 \mathrm{a}$ & $2,3 \mathrm{a}$ & $10-6$ & $1,5 \mathrm{a}$ & $2,1 \mathrm{~b}$ \\
\hline $09-3$ & $3,2 \mathrm{a}$ & $2,8 \mathrm{a}$ & $34-6$ & $2,0 \mathrm{a}$ & $2,3 \mathrm{a}$ & $27-5$ & $2,8 \mathrm{a}$ & $2,1 \mathrm{~b}$ \\
\hline $07-2$ & $2,0 \mathrm{a}$ & $2,8 \mathrm{a}$ & $33-1$ & $1,8 \mathrm{a}$ & $2,3 \mathrm{a}$ & $25-5$ & $2,1 \mathrm{a}$ & $2,1 \mathrm{~b}$ \\
\hline $03-2$ & $1,7 \mathrm{a}$ & $2,8 \mathrm{a}$ & $32-4$ & $1,6 \mathrm{a}$ & $2,3 \mathrm{a}$ & $19-5$ & $2,1 \mathrm{a}$ & $2,1 \mathrm{~b}$ \\
\hline $35-6$ & $1,8 \mathrm{a}$ & $2,7 \mathrm{a}$ & $25-6$ & $1,7 \mathrm{a}$ & $2,3 \mathrm{a}$ & $10-5$ & $2,2 \mathrm{a}$ & $2,1 \mathrm{~b}$ \\
\hline $35-5$ & $2,6 \mathrm{a}$ & $2,7 \mathrm{a}$ & $01-6$ & $1,5 \mathrm{a}$ & $2,3 \mathrm{a}$ & $27-4$ & $1,7 \mathrm{a}$ & $2,1 \mathrm{~b}$ \\
\hline $02-6$ & $2,1 \mathrm{a}$ & $2,7 \mathrm{a}$ & $28-5$ & $1,8 \mathrm{a}$ & $2,3 \mathrm{a}$ & $19-4$ & $1,7 \mathrm{a}$ & $2,1 \mathrm{~b}$ \\
\hline $21-5$ & $1,8 \mathrm{a}$ & $2,7 \mathrm{a}$ & $15-5$ & $2,1 \mathrm{a}$ & $2,3 \mathrm{a}$ & $22-3$ & $2,0 \mathrm{a}$ & $2,1 \mathrm{~b}$ \\
\hline $16-5$ & $2,3 \mathrm{a}$ & $2,7 \mathrm{a}$ & $12-5$ & $1,8 \mathrm{a}$ & $2,3 \mathrm{a}$ & $19-3$ & $1,5 \mathrm{a}$ & $2,1 \mathrm{~b}$ \\
\hline $07-3$ & $1,6 \mathrm{a}$ & $2,7 \mathrm{a}$ & $30-4$ & $2,2 \mathrm{a}$ & $2,3 \mathrm{a}$ & $12-3$ & $1,6 \mathrm{a}$ & $2,1 \mathrm{~b}$ \\
\hline $26-2$ & $2,5 \mathrm{a}$ & $2,7 \mathrm{a}$ & $15-4$ & $2,1 \mathrm{a}$ & $2,3 \mathrm{a}$ & $10-3$ & $2,2 \mathrm{a}$ & $2,1 \mathrm{~b}$ \\
\hline $24-2$ & $2,2 \mathrm{a}$ & $2,7 \mathrm{a}$ & $12-4$ & $2,1 \mathrm{a}$ & $2,3 \mathrm{a}$ & $08-3$ & $2,1 \mathrm{a}$ & $2,1 \mathrm{~b}$ \\
\hline $16-2$ & $2,0 \mathrm{a}$ & $2,7 \mathrm{a}$ & $31-3$ & $1,5 \mathrm{a}$ & $2,3 \mathrm{a}$ & $05-3$ & $2,0 \mathrm{a}$ & $2,1 \mathrm{~b}$ \\
\hline $02-2$ & $2,1 \mathrm{a}$ & $2,7 \mathrm{a}$ & $28-3$ & $2,0 \mathrm{a}$ & $2,3 \mathrm{a}$ & $23-2$ & $2,5 \mathrm{a}$ & $2,1 \mathrm{~b}$ \\
\hline $26-1$ & $2,1 \mathrm{a}$ & $2,7 \mathrm{a}$ & $25-3$ & $2,2 \mathrm{a}$ & $2,3 \mathrm{a}$ & $19-2$ & $2,0 \mathrm{a}$ & $2,1 \mathrm{~b}$ \\
\hline $25-1$ & $1,6 \mathrm{a}$ & $2,7 \mathrm{a}$ & $18-3$ & $2,0 \mathrm{a}$ & $2,3 \mathrm{a}$ & $12-2$ & $1,7 \mathrm{a}$ & $2,1 \mathrm{~b}$ \\
\hline $02-1$ & $3,3 \mathrm{a}$ & $2,7 \mathrm{a}$ & $16-3$ & $2,3 \mathrm{a}$ & $2,3 \mathrm{a}$ & $11-2$ & $1,5 \mathrm{a}$ & $2,1 \mathrm{~b}$ \\
\hline $34-5$ & $2,2 \mathrm{a}$ & $2,6 \mathrm{a}$ & $11-3$ & $2,2 \mathrm{a}$ & $2,3 \mathrm{a}$ & $10-2$ & $2,2 \mathrm{a}$ & $2,1 \mathrm{~b}$ \\
\hline $32-6$ & $1,7 \mathrm{a}$ & $2,6 \mathrm{a}$ & $03-3$ & $1,2 \mathrm{a}$ & $2,3 \mathrm{a}$ & $30-1$ & $1,7 \mathrm{a}$ & $2,1 \mathrm{~b}$ \\
\hline $30-2$ & $1,5 \mathrm{a}$ & $2,6 \mathrm{a}$ & $27-2$ & $2,1 \mathrm{a}$ & $2,3 \mathrm{a}$ & $29-1$ & $2,1 \mathrm{a}$ & $2,1 \mathrm{~b}$ \\
\hline $28-6$ & $1,7 \mathrm{a}$ & $2,6 \mathrm{a}$ & $25-2$ & $2,3 \mathrm{a}$ & $2,3 \mathrm{a}$ & $27-1$ & $1,8 \mathrm{a}$ & $2,1 \mathrm{~b}$ \\
\hline $03-5$ & $1,7 \mathrm{a}$ & $2,6 \mathrm{a}$ & $20-2$ & $3,2 \mathrm{a}$ & $2,3 \mathrm{a}$ & $15-1$ & $1,6 \mathrm{a}$ & $2,1 \mathrm{~b}$ \\
\hline $02-5$ & $2,6 \mathrm{a}$ & $2,6 \mathrm{a}$ & $08-2$ & $1,2 \mathrm{a}$ & $2,3 \mathrm{a}$ & $34-4$ & $2,1 \mathrm{a}$ & $2,0 \mathrm{~b}$ \\
\hline $28-4$ & $2,5 \mathrm{a}$ & $2,6 \mathrm{a}$ & $06-2$ & $2,0 \mathrm{a}$ & $2,3 \mathrm{a}$ & $30-6$ & $1,8 \mathrm{a}$ & $2,0 \mathrm{~b}$ \\
\hline $25-4$ & $1,6 \mathrm{a}$ & $2,6 \mathrm{a}$ & $18-1$ & $1,8 \mathrm{a}$ & $2,3 \mathrm{a}$ & $12-6$ & $1,8 \mathrm{a}$ & $2,0 \mathrm{~b}$ \\
\hline $18-4$ & $2,0 \mathrm{a}$ & $2,6 \mathrm{a}$ & $11-1$ & $1,7 \mathrm{a}$ & $2,3 \mathrm{a}$ & $22-5$ & $2,1 \mathrm{a}$ & $2,0 \mathrm{~b}$ \\
\hline $02-4$ & $2,0 \mathrm{a}$ & $2,6 \mathrm{a}$ & $09-1$ & $2,6 \mathrm{a}$ & $2,3 \mathrm{a}$ & $20-5$ & $2,1 \mathrm{a}$ & $2,0 \mathrm{~b}$ \\
\hline $15-2$ & $2,0 \mathrm{a}$ & $2,6 \mathrm{a}$ & $08-1$ & $2,3 \mathrm{a}$ & $2,3 \mathrm{a}$ & $18-5$ & $2,2 \mathrm{a}$ & $2,0 \mathrm{~b}$ \\
\hline $14-2$ & $2,0 \mathrm{a}$ & $2,6 \mathrm{a}$ & $35-3$ & $2,2 \mathrm{a}$ & $2,2 \mathrm{~b}$ & $27-3$ & $1,8 \mathrm{a}$ & $2,0 \mathrm{~b}$ \\
\hline $10-1$ & $1,6 \mathrm{a}$ & $2,6 \mathrm{a}$ & $35-2$ & $2,2 \mathrm{a}$ & $2,2 \mathrm{~b}$ & $28-2$ & $2,2 \mathrm{a}$ & $2,0 \mathrm{~b}$ \\
\hline $07-1$ & $1,7 \mathrm{a}$ & $2,6 \mathrm{a}$ & $35-1$ & $2,2 \mathrm{a}$ & $2,2 \mathrm{~b}$ & $31-1$ & $1,8 \mathrm{a}$ & $2,0 \mathrm{~b}$ \\
\hline 04-1 & $2,2 \mathrm{a}$ & $2,6 \mathrm{a}$ & $34-1$ & $2,5 \mathrm{a}$ & $2,2 \mathrm{~b}$ & $22-1$ & $2,0 \mathrm{a}$ & $2,0 \mathrm{~b}$ \\
\hline 03-1 & $2,0 \mathrm{a}$ & $2,6 \mathrm{a}$ & $33-5$ & $1,7 \mathrm{a}$ & $2,2 \mathrm{~b}$ & $21-1$ & $2,7 \mathrm{a}$ & $2,0 \mathrm{~b}$ \\
\hline $33-6$ & $1,6 \mathrm{a}$ & $2,5 \mathrm{a}$ & $33-3$ & $2,0 \mathrm{a}$ & $2,2 \mathrm{~b}$ & $12-1$ & $1,8 \mathrm{a}$ & $2,0 \mathrm{~b}$ \\
\hline $32-3$ & $2,5 \mathrm{a}$ & $2,5 \mathrm{a}$ & $33-2$ & $1,7 \mathrm{a}$ & $2,2 \mathrm{~b}$ & $22-2$ & $2,3 \mathrm{a}$ & $1,8 \mathrm{~b}$ \\
\hline $32-2$ & $1,7 \mathrm{a}$ & $2,5 \mathrm{a}$ & $32-5$ & $1,8 \mathrm{a}$ & $2,2 \mathrm{~b}$ & $05-2$ & $2,0 \mathrm{a}$ & $1,8 \mathrm{~b}$ \\
\hline $32-1$ & $1,6 \mathrm{a}$ & $2,5 \mathrm{a}$ & $21-6$ & $1,8 \mathrm{a}$ & $2,2 \mathrm{~b}$ & $28-1$ & $1,8 \mathrm{a}$ & $1,8 \mathrm{~b}$ \\
\hline
\end{tabular}


Continuação Tabela 3

\begin{tabular}{lllllllll}
\hline $31-2$ & $1,7 \mathrm{a}$ & $2,5 \mathrm{a}$ & $19-6$ & $1,2 \mathrm{a}$ & $2,2 \mathrm{~b}$ & $05-1$ & $2,5 \mathrm{a}$ & $1,8 \mathrm{~b}$ \\
$22-6$ & $2,5 \mathrm{a}$ & $2,5 \mathrm{a}$ & $15-6$ & $1,6 \mathrm{a}$ & $2,2 \mathrm{~b}$ & $29-2$ & $2,5 \mathrm{a}$ & $1,7 \mathrm{~b}$ \\
$18-6$ & $1,5 \mathrm{a}$ & $2,5 \mathrm{a}$ & $10-4$ & $1,6 \mathrm{a}$ & $2,2 \mathrm{~b}$ & $30-5$ & $1,7 \mathrm{a}$ & $1,7 \mathrm{~b}$ \\
$03-6$ & $1,6 \mathrm{a}$ & $2,5 \mathrm{a}$ & $03-4$ & $1,8 \mathrm{a}$ & $2,2 \mathrm{~b}$ & $30-3$ & $2,2 \mathrm{a}$ & $1,7 \mathrm{~b}$ \\
$01-5$ & $1,8 \mathrm{a}$ & $2,5 \mathrm{a}$ & $21-3$ & $1,7 \mathrm{a}$ & $2,2 \mathrm{~b}$ & $17-2$ & $3,5 \mathrm{a}$ & $1,7 \mathrm{~b}$ \\
$22-4$ & $1,6 \mathrm{a}$ & $2,5 \mathrm{a}$ & $15-3$ & $1,8 \mathrm{a}$ & $2,2 \mathrm{~b}$ & $23-1$ & $2,3 \mathrm{a}$ & $1,7 \mathrm{~b}$ \\
$20-4$ & $1,7 \mathrm{a}$ & $2,5 \mathrm{a}$ & $01-3$ & $2,0 \mathrm{a}$ & $2,2 \mathrm{~b}$ & $06-1$ & $2,3 \mathrm{a}$ & $1,6 \mathrm{~b}$ \\
$16-4$ & $2,3 \mathrm{a}$ & $2,5 \mathrm{a}$ & $21-2$ & $2,0 \mathrm{a}$ & $2,2 \mathrm{~b}$ & BR 106 & $2,2 \mathrm{a}$ & $1,5 \mathrm{~b}$ \\
$01-4$ & $2,0 \mathrm{a}$ & $2,5 \mathrm{a}$ & $18-2$ & $1,6 \mathrm{a}$ & $2,2 \mathrm{~b}$ & AS1522 & $1,8 \mathrm{a}$ & $1,3 \mathrm{~b}$ \\
$26-3$ & $2,3 \mathrm{a}$ & $2,5 \mathrm{a}$ & $01-2$ & $2,2 \mathrm{a}$ & $2,2 \mathrm{~b}$ & $34-2$ & $2,2 \mathrm{a}$ & $1,3 \mathrm{~b}$ \\
$06-3$ & $1,7 \mathrm{a}$ & $2,5 \mathrm{a}$ & $24-1$ & $1,6 \mathrm{a}$ & $2,2 \mathrm{~b}$ & $21-4$ & $2,3 \mathrm{a}$ & $1,2 \mathrm{~b}$ \\
$09-2$ & $2,5 \mathrm{a}$ & $2,5 \mathrm{a}$ & $16-1$ & $2,2 \mathrm{a}$ & $2,2 \mathrm{~b}$ & Média & 2,03 & 2,32 \\
$20-1$ & $2,7 \mathrm{a}$ & $2,5 \mathrm{a}$ & $01-1$ & $1,5 \mathrm{a}$ & $2,2 \mathrm{~b}$ & C.V. (\%) & 32,73 & 21,7 \\
\hline
\end{tabular}

Médias seguidas de mesma letra não diferem entre si a 5\% de significância pelo teste Scott e Knott

A média desta característica foi 3,6, ou seja, cor intermediária entre amarelo alaranjado e alaranjado, e o coeficiente de variação baixo, 12,7\%. Segundo Rodrigues et al. (2009) e Moraes (2010), na comercialização de espigas de milho in natura, é preferível que a coloração seja amarela. Porém, segundo Oliveira et al. (2007), para a indústria de frangos de corte e galinhas de postura, o milho de coloração amarelo-laranja é o tipo desejado, pois confere aos frangos pele e pernas amareladas, bem como gemas dos ovos de cor amarelo-laranja. Essas características têm valores econômicos muito apreciados no mercado consumidor. Os genótipos dos grupos de maiores médias e médias intermediárias apresentam notas variando de 3,6 a 4,6, correspondente à cor próxima a amarela alaranjada, com exceção apenas do genótipo 10-6, com nota 5,3, correspondente à cor alaranjada, somando então 90 genótipos. Considerando-se estes genótipos com cores desejadas pela indústria de frangos de corte e galinhas de postura.

Segundo Albuquerque et al. (2008), a cor de grão é uma característica indispensável para a avaliação de milho verde. No grupo estatístico inferior, as notas variam de 2,5 a 3,5 , correspondendo à cor próxima a amarelo, sendo estes 70 genótipos adequados para o consumo in natura com base na cor de grão.

A cor dos grãos do milho verde exerce grande influência na aceitação pelo consumidor. De acordo com Pereira Filho et al. (2003), as espigas com grãos de coloração mais clara são preferidas quando o produto é destinado ao consumo de milho verde in natura, além do quê, cor amarela apresenta correlação significativa com o maior tempo de comercialização na embalagem de isopor com filme plástico, indicando que as cores mais aceitáveis no mercado consumidor possuem maior tempo de prateleira (ALBUQUERQUE et al., 2008).
Quanto ao tipo de grão (TAB. 4), foram formados dois grupos, sendo que o grupo de maiores médias apresenta 55 genótipos e o grupo de menores médias, 105 genótipos. A média desta característica foi de 1,48, ou seja, tipo de grão entre duro e semi-duro.

No milho dentado, o endosperma é duro nos lados e amiláceo no centro do grão, sendo um caráter poligênico. Este tipo de milho é o mais produzido no mundo. Já o milho duro contém um endosperma mais denso e cristalino que ocupa quase todo o seu volume, sendo a proporção amilácea muito reduzida. Este caráter é poligênico e o grão duro, geralmente, é o que apresenta maior densidade. No setor moageiro, obtém-se melhor rendimento industrial quando se utiliza grãos uniformes e densos do tipo duro (OLIVEIRA et al., 2007). Dessa forma, os 105 genótipos do grupo inferior se enquadram nestas características, com notas 1,0 a 1,5, ou seja, grãos tipo duro.

Já nos grãos tipo dentado, o endosperma amiláceo torna-se de maior interesse para o consumo in natura devido a sua maciez (PEREIRA FILHO; CRUZ, 2002). Mesmo não diferindo dos demais genótipos do grupo superior, os genótipos 12-2 e 34-2 apresentaram notas de tipo de grão próximo a semidentado, indicando uma possibilidade de utilização desses materiais para o consumo in natura ou processamento como produção de pamonha. Segundo Rodrigues et al. (2009), os grãos devem ser, preferencialmente, do tipo dentado quando voltados para o consumo in natura e o endurecimento dos grãos deve ser relativamente lento, para evitar o trincamento do endosperma, e o pericarpo, fino, conferindo assim maior maciez dos grãos após o cozimento.

Oliveira et al. (2007) também afirmam que grãos duros tendem a apresentar coloração ligeiramente mais 
Tabela 4 - Médias de cor da coroa dos grãos (Cor) e tipo de grão (Tipo) de 160 genótipos de milho em Gurupi - TO, 2009

\begin{tabular}{|c|c|c|c|c|c|c|c|c|}
\hline Genótipos & Cor & Tipo & Genótipos & Cor & Tipo & Genótipos & Cor & Tipo \\
\hline $02-1$ & $3,2 \mathrm{c}$ & $2,7 \mathrm{a}$ & BR106 & $3,6 \mathrm{~b}$ & $1,6 \mathrm{a}$ & $21-3$ & $3,6 \mathrm{~b}$ & $1,2 \mathrm{~b}$ \\
\hline $02-2$ & $3,2 \mathrm{c}$ & $2,7 \mathrm{a}$ & 01-1 & $3,3 \mathrm{c}$ & $1,5 \mathrm{~b}$ & $25-3$ & $3,6 \mathrm{~b}$ & $1,2 \mathrm{~b}$ \\
\hline $01-5$ & $3,1 \mathrm{c}$ & $2,5 \mathrm{a}$ & $03-1$ & $2,7 \mathrm{c}$ & $1,5 \mathrm{~b}$ & $12-4$ & $4,2 \mathrm{a}$ & $1,2 \mathrm{~b}$ \\
\hline $10-5$ & $3,6 \mathrm{~b}$ & $2,5 \mathrm{a}$ & $19-1$ & $3,7 \mathrm{~b}$ & $1,5 \mathrm{~b}$ & $15-4$ & $3,7 \mathrm{~b}$ & $1,2 \mathrm{~b}$ \\
\hline $25-1$ & $3,1 \mathrm{c}$ & $2,3 \mathrm{a}$ & $31-1$ & $3,0 \mathrm{c}$ & $1,5 \mathrm{~b}$ & $18-4$ & $3,5 \mathrm{c}$ & $1,2 \mathrm{~b}$ \\
\hline $27-4$ & $4,0 \mathrm{a}$ & $2,3 \mathrm{a}$ & $03-2$ & $3,0 \mathrm{c}$ & $1,5 \mathrm{~b}$ & $22-5$ & $4,0 \mathrm{a}$ & $1,2 \mathrm{~b}$ \\
\hline $32-1$ & $3,3 \mathrm{c}$ & $2,3 \mathrm{a}$ & $09-2$ & $3,1 \mathrm{c}$ & $1,5 \mathrm{~b}$ & $03-6$ & $3,3 \mathrm{c}$ & $1,2 \mathrm{~b}$ \\
\hline $34-4$ & $3,3 \mathrm{c}$ & $2,3 \mathrm{a}$ & $10-2$ & $3,8 \mathrm{~b}$ & $1,5 \mathrm{~b}$ & $33-2$ & $3,7 \mathrm{~b}$ & $1,2 \mathrm{~b}$ \\
\hline $34-5$ & $3,5 \mathrm{c}$ & $2,3 \mathrm{a}$ & $22-2$ & $3,3 \mathrm{c}$ & $1,5 \mathrm{~b}$ & $33-4$ & $3,6 \mathrm{~b}$ & $1,2 \mathrm{~b}$ \\
\hline $09-1$ & $3,1 \mathrm{c}$ & $2,2 \mathrm{a}$ & $01-3$ & $3,2 \mathrm{c}$ & $1,5 \mathrm{~b}$ & $35-2$ & $3,7 \mathrm{~b}$ & $1,2 \mathrm{~b}$ \\
\hline $02-4$ & $3,3 \mathrm{c}$ & $2,1 \mathrm{a}$ & $19-3$ & $3,5 \mathrm{c}$ & $1,5 \mathrm{~b}$ & $35-4$ & $3,8 \mathrm{~b}$ & $1,2 \mathrm{~b}$ \\
\hline $34-1$ & $3,2 \mathrm{c}$ & $2,1 \mathrm{a}$ & $20-3$ & $3,0 \mathrm{c}$ & $1,5 \mathrm{~b}$ & $35-5$ & $3,7 \mathrm{~b}$ & $1,2 \mathrm{~b}$ \\
\hline $11-1$ & $3,5 \mathrm{c}$ & $2,0 \mathrm{a}$ & $22-3$ & $4,1 \mathrm{a}$ & $1,5 \mathrm{~b}$ & $05-1$ & $3,3 \mathrm{c}$ & $1,1 \mathrm{~b}$ \\
\hline $15-1$ & $3,1 \mathrm{c}$ & $2,0 \mathrm{a}$ & $03-4$ & $3,2 \mathrm{c}$ & $1,5 \mathrm{~b}$ & $08-1$ & $3,8 \mathrm{~b}$ & $1,1 \mathrm{~b}$ \\
\hline $02-3$ & $3,3 \mathrm{c}$ & $2,0 \mathrm{a}$ & $28-4$ & $4,0 \mathrm{a}$ & $1,5 \mathrm{~b}$ & $14-1$ & $4,0 \mathrm{a}$ & $1,1 \mathrm{~b}$ \\
\hline $11-3$ & $3,8 \mathrm{~b}$ & $2,0 \mathrm{a}$ & $25-5$ & $4,5 \mathrm{a}$ & $1,5 \mathrm{~b}$ & $27-1$ & $3,7 \mathrm{~b}$ & $1,1 \mathrm{~b}$ \\
\hline $03-5$ & $3,1 \mathrm{c}$ & $2,0 \mathrm{a}$ & $28-5$ & $3,8 \mathrm{~b}$ & $1,5 \mathrm{~b}$ & $30-1$ & $3,5 \mathrm{c}$ & $1,1 \mathrm{~b}$ \\
\hline $25-6$ & $3,8 \mathrm{~b}$ & $2,0 \mathrm{a}$ & $19-6$ & $4,2 \mathrm{a}$ & $1,5 \mathrm{~b}$ & $12-2$ & $3,6 \mathrm{~b}$ & $1,1 \mathrm{~b}$ \\
\hline $34-2$ & $3,6 \mathrm{~b}$ & $2,0 \mathrm{a}$ & $32-4$ & $3,6 \mathrm{~b}$ & $1,5 \mathrm{~b}$ & $24-2$ & $4,2 \mathrm{a}$ & $1,1 \mathrm{~b}$ \\
\hline $36-1$ & $2,7 \mathrm{c}$ & $2,0 \mathrm{a}$ & $36-2$ & $3,2 \mathrm{c}$ & $1,5 \mathrm{~b}$ & $06-3$ & $4,1 \mathrm{a}$ & $1,1 \mathrm{~b}$ \\
\hline $14-2$ & $3,5 \mathrm{c}$ & $1,8 \mathrm{a}$ & $06-1$ & $4,0 \mathrm{a}$ & $1,3 \mathrm{~b}$ & $01-4$ & $3,5 \mathrm{c}$ & $1,1 \mathrm{~b}$ \\
\hline $15-2$ & $3,2 \mathrm{c}$ & $1,8 \mathrm{a}$ & $10-1$ & $3,1 \mathrm{c}$ & $1,3 \mathrm{~b}$ & $12-5$ & $3,6 \mathrm{~b}$ & $1,1 \mathrm{~b}$ \\
\hline $19-2$ & $3,2 \mathrm{c}$ & $1,8 \mathrm{a}$ & $12-1$ & $3,2 \mathrm{c}$ & $1,3 \mathrm{~b}$ & $16-5$ & $4,1 \mathrm{a}$ & $1,1 \mathrm{~b}$ \\
\hline $27-2$ & $3,6 \mathrm{~b}$ & $1,8 \mathrm{a}$ & $28-1$ & $4,3 \mathrm{a}$ & $1,3 \mathrm{~b}$ & $30-5$ & $4,1 \mathrm{a}$ & $1,1 \mathrm{~b}$ \\
\hline $25-4$ & $4,0 \mathrm{a}$ & $1,8 \mathrm{a}$ & $06-2$ & $4,1 \mathrm{a}$ & $1,3 \mathrm{~b}$ & $12-6$ & $3,8 \mathrm{~b}$ & $1,1 \mathrm{~b}$ \\
\hline $21-5$ & $3,7 \mathrm{~b}$ & $1,8 \mathrm{a}$ & $07-2$ & $3,1 \mathrm{c}$ & $1,3 \mathrm{~b}$ & $15-6$ & $3,0 \mathrm{c}$ & $1,1 \mathrm{~b}$ \\
\hline $02-6$ & $3,1 \mathrm{c}$ & $1,8 \mathrm{a}$ & $11-2$ & $3,7 \mathrm{~b}$ & $1,3 \mathrm{~b}$ & $30-6$ & $4,3 \mathrm{a}$ & $1,1 \mathrm{~b}$ \\
\hline $22-6$ & $3,8 \mathrm{~b}$ & $1,8 \mathrm{a}$ & $16-2$ & $3,5 \mathrm{c}$ & $1,3 \mathrm{~b}$ & $33-1$ & $3,3 \mathrm{c}$ & $1,1 \mathrm{~b}$ \\
\hline $32-3$ & $3,3 \mathrm{c}$ & $1,8 \mathrm{a}$ & $03-3$ & $3,0 \mathrm{c}$ & $1,3 \mathrm{~b}$ & $33-3$ & $3,7 \mathrm{~b}$ & $1,1 \mathrm{~b}$ \\
\hline $13-1$ & $4,0 \mathrm{a}$ & $1,7 \mathrm{a}$ & $07-3$ & $3,6 \mathrm{~b}$ & $1,3 \mathrm{~b}$ & $33-5$ & $2,6 \mathrm{c}$ & $1,1 \mathrm{~b}$ \\
\hline $22-1$ & $3,2 \mathrm{c}$ & $1,7 \mathrm{a}$ & $10-3$ & $4,3 \mathrm{a}$ & $1,3 \mathrm{~b}$ & AS1522 & $3,1 \mathrm{c}$ & $1,1 \mathrm{~b}$ \\
\hline $23-1$ & $3,3 \mathrm{c}$ & $1,7 \mathrm{a}$ & $15-3$ & $3,6 \mathrm{~b}$ & $1,3 \mathrm{~b}$ & 04-1 & $3,6 \mathrm{~b}$ & $1,0 \mathrm{~b}$ \\
\hline $26-1$ & $3,7 \mathrm{~b}$ & $1,7 \mathrm{a}$ & $26-3$ & $3,7 \mathrm{~b}$ & $1,3 \mathrm{~b}$ & $16-1$ & $4,0 \mathrm{a}$ & $1,0 \mathrm{~b}$ \\
\hline $20-2$ & $3,2 \mathrm{c}$ & $1,7 \mathrm{a}$ & $28-3$ & $4,1 \mathrm{a}$ & $1,3 \mathrm{~b}$ & $17-1$ & $4,5 \mathrm{a}$ & $1,0 \mathrm{~b}$ \\
\hline $23-2$ & $3,7 \mathrm{~b}$ & $1,7 \mathrm{a}$ & $10-4$ & $3,1 \mathrm{c}$ & $1,3 \mathrm{~b}$ & $18-1$ & $4,1 \mathrm{a}$ & $1,0 \mathrm{~b}$ \\
\hline $26-2$ & $3,5 \mathrm{c}$ & $1,7 \mathrm{a}$ & $16-4$ & $3,2 \mathrm{c}$ & $1,3 \mathrm{~b}$ & $24-1$ & $3,6 \mathrm{~b}$ & $1,0 \mathrm{~b}$ \\
\hline $02-5$ & $3,1 \mathrm{c}$ & $1,7 \mathrm{a}$ & $20-4$ & $3,5 \mathrm{c}$ & $1,3 \mathrm{~b}$ & $08-2$ & $3,8 \mathrm{~b}$ & $1,0 \mathrm{~b}$ \\
\hline $15-5$ & $3,1 \mathrm{c}$ & $1,7 \mathrm{a}$ & $22-4$ & $3,5 \mathrm{c}$ & $1,3 \mathrm{~b}$ & $17-2$ & $4,0 \mathrm{a}$ & $1,0 \mathrm{~b}$ \\
\hline $01-6$ & $3,6 \mathrm{~b}$ & $1,7 \mathrm{a}$ & $18-5$ & $3,2 \mathrm{c}$ & $1,3 \mathrm{~b}$ & $05-3$ & $4,1 \mathrm{a}$ & $1,0 \mathrm{~b}$ \\
\hline $21-6$ & $3,6 \mathrm{~b}$ & $1,7 \mathrm{a}$ & $20-5$ & $3,1 \mathrm{c}$ & $1,3 \mathrm{~b}$ & $08-3$ & $3,8 \mathrm{~b}$ & $1,0 \mathrm{~b}$ \\
\hline $32-2$ & $3,2 \mathrm{c}$ & $1,7 \mathrm{a}$ & $10-6$ & $5,3 \mathrm{a}$ & $1,3 \mathrm{~b}$ & $18-3$ & $3,6 \mathrm{~b}$ & $1,0 \mathrm{~b}$ \\
\hline
\end{tabular}


Continuação Tabela 4

\begin{tabular}{lllllllll}
\hline $35-1$ & $3,7 \mathrm{~b}$ & $1,7 \mathrm{a}$ & $18-6$ & $3,6 \mathrm{~b}$ & $1,3 \mathrm{~b}$ & $24-3$ & $3,3 \mathrm{c}$ & $1,0 \mathrm{~b}$ \\
$07-1$ & $3,3 \mathrm{c}$ & $1,6 \mathrm{a}$ & $29-2$ & $3,6 \mathrm{~b}$ & $1,3 \mathrm{~b}$ & $27-3$ & $3,5 \mathrm{c}$ & $1,0 \mathrm{~b}$ \\
$29-1$ & $3,7 \mathrm{~b}$ & $1,6 \mathrm{a}$ & $32-5$ & $3,7 \mathrm{~b}$ & $1,3 \mathrm{~b}$ & $30-3$ & $4,2 \mathrm{a}$ & $1,0 \mathrm{~b}$ \\
$01-2$ & $3,7 \mathrm{~b}$ & $1,6 \mathrm{a}$ & $32-6$ & $3,2 \mathrm{c}$ & $1,3 \mathrm{~b}$ & $31-3$ & $3,1 \mathrm{c}$ & $1,0 \mathrm{~b}$ \\
$21-2$ & $3,8 \mathrm{~b}$ & $1,6 \mathrm{a}$ & $33-6$ & $3,8 \mathrm{~b}$ & $1,3 \mathrm{~b}$ & $30-4$ & $4,6 \mathrm{a}$ & $1,0 \mathrm{~b}$ \\
$25-2$ & $4,1 \mathrm{a}$ & $1,6 \mathrm{a}$ & $34-3$ & $3,2 \mathrm{c}$ & $1,3 \mathrm{~b}$ & $19-5$ & $4,0 \mathrm{a}$ & $1,0 \mathrm{~b}$ \\
$09-3$ & $3,6 \mathrm{~b}$ & $1,6 \mathrm{a}$ & $20-1$ & $3,3 \mathrm{c}$ & $1,2 \mathrm{~b}$ & $16-6$ & $3,5 \mathrm{c}$ & $1,0 \mathrm{~b}$ \\
$19-4$ & $3,6 \mathrm{~b}$ & $1,6 \mathrm{a}$ & $21-1$ & $3,8 \mathrm{~b}$ & $1,2 \mathrm{~b}$ & $30-2$ & $3,8 \mathrm{~b}$ & $1,0 \mathrm{~b}$ \\
$21-4$ & $3,7 \mathrm{~b}$ & $1,6 \mathrm{a}$ & $05-2$ & $3,6 \mathrm{~b}$ & $1,2 \mathrm{~b}$ & $31-2$ & $3,2 \mathrm{c}$ & $1,0 \mathrm{~b}$ \\
$27-5$ & $3,2 \mathrm{c}$ & $1,6 \mathrm{a}$ & $18-2$ & $3,7 \mathrm{~b}$ & $1,2 \mathrm{~b}$ & $35-3$ & $4,0 \mathrm{a}$ & $1,0 \mathrm{~b}$ \\
$20-6$ & $3,6 \mathrm{~b}$ & $1,6 \mathrm{a}$ & $28-2$ & $4,1 \mathrm{a}$ & $1,2 \mathrm{~b}$ & $35-6$ & $3,7 \mathrm{~b}$ & $1,0 \mathrm{~b}$ \\
$28-6$ & $3,6 \mathrm{~b}$ & $1,6 \mathrm{a}$ & $12-3$ & $3,6 \mathrm{~b}$ & $1,2 \mathrm{~b}$ & Média & 3,61 & 1,48 \\
$34-6$ & $3,1 \mathrm{c}$ & $1,6 \mathrm{a}$ & $16-3$ & $3,5 \mathrm{c}$ & $1,2 \mathrm{~b}$ & C.V. $(\%)$ & 12,7 & 37,0 \\
\hline
\end{tabular}

Médias seguidas de mesma letra não diferem entre si a 5\% de significância pelo teste Scott e Knott

intensa do que os do tipo dentado. Assim, a seleção de materiais de tipo de grãos dentado, considerado de maior interesse para o mercado consumidor, também irá selecionar, por consequência, grãos de cor amarelada e de maior interesse comercial para o consumo in natura.

Para o peso de 100 sementes (TAB. 5) também se observam dois grupos estatísticos, com 76 genótipos no grupo inferior e 84 genótipos no grupo superior. $\mathrm{O}$ peso médio de 100 sementes foi $29,4 \mathrm{~g}$ e o coeficiente de variação de baixo valor, 14,8\%.

A variação do grupo de maiores pesos de 100 sementes foi de 29,3 a 38,6 g, e a variação do grupo de menores pesos de 100 sementes foi de 19,3 a 29,2 g. O híbrido comercial AS1522 apresentou $26 \mathrm{~g}$ de peso de 100 sementes, e a variedade BR106, 32,4 g, estando este no grupo superior. Segundo Matsushima (1970), essa característica é afetada mais intensamente por fatores genéticos do que abióticos, concordando com o resultado do presente trabalho.

A avaliação do peso de 100 sementes é importante para o cálculo da quantidade de sementes a ser semeada em um plantio comercial. Miranda et al. (2003) e Cancellier et al. (2011) afirmam que esta característica é altamente correlacionada com a produtividade de grãos, podendo ser utilizada para seleção visando ao aumento da produtividade. Guimarães et al. (2008) comentam que quando há correlações positivas entre massa de 100 grãos e a produtividade, estas características podem ser consideradas prioritárias em programas de melhoramento que visem a obter cultivares mais produtivas.

Carneiro (2002) avaliou o peso de 100 grãos da população de polinização aberta de milho-pipoca e constatou que apresentavam valor de 10,12 a 16,03, indicando que para plantio de um hectare é necessário no máximo $9 \mathrm{~kg}$ de sementes comerciais. No presente trabalho, para o genótipo de menor peso de 100 sementes (07-3), com 19,3 g, seriam necessários aproximadamente $10 \mathrm{~kg}$ de sementes para o plantio de um hectare, enquanto para o genótipo de maior peso de 100 sementes (25-5), com 38,6 g, pouco mais de $21,2 \mathrm{~kg}$, considerando-se uma população de 55 mil plantas ha-1 .

Em relação à produtividade (TAB. 5), os genótipos foram diferenciados por dois grupos, sendo 89 genótipos pertencentes ao grupo de maior produtividade, com valores variando de 4555 a $6726 \mathrm{~kg} \mathrm{ha}^{-1}$, e 71 genótipos no grupo inferior, com uma variação nas médias de 2903 a $4527 \mathrm{~kg} \mathrm{ha}^{-1}$. Também foi observado um baixo coeficiente de variação para esta característica, indicando uma boa precisão na avaliação da produtividade.

A produtividade média do experimento foi de $4594 \mathrm{~kg} \mathrm{ha}^{-1}$, estando, portanto, acima da média do Estado do Tocantins que, na mesma safra, foi de $3158 \mathrm{~kg} \mathrm{ha}^{-1}$ (CONAB, 2010). Mesmo o genótipo de menor produtividade, atingindo $2903 \mathrm{~kg} \mathrm{ha}^{-1}$, ainda assim encontra-se próximo da média do Estado, indicando que os genótipos do Programa de Melhoramento de Milho da Universidade Federal do Tocantins possuem potencial para o desenvolvimento de genótipos comerciais para utilização nas condições edafoclimáticas do Estado do Tocantins.

Cancellier et al. (2011) avaliando populações de milho oriundas do mesmo programa de melhoramento observaram uma variação significativa na produtividade, com 4086 a $6348 \mathrm{~kg} \mathrm{ha}^{-1}$, indicando um grande potencial para o desenvolvimento de cultivares adaptados para a região e com produtividades satisfatórias. 
Tabela 5 - Médias de peso de 100 sementes em g (P100S) e produtividade em kg ha-1 (Prod) de 160 genótipos de milho em Gurupi - TO, 2009

\begin{tabular}{|c|c|c|c|c|c|c|c|c|}
\hline Genótipos & P100S & Prod & Genótipos & P100S & Prod & Genótipos & P100S & Prod \\
\hline $02-5$ & $29,2 \mathrm{~b}$ & $6726 a$ & $22-6$ & $32,9 \mathrm{a}$ & 4869 a & $07-2$ & $22,5 \mathrm{~b}$ & $4315 b$ \\
\hline $12-5$ & $32,5 \mathrm{a}$ & $6564 \mathrm{a}$ & $21-1$ & $30,4 \mathrm{a}$ & $4868 \mathrm{a}$ & $12-1$ & $33,4 \mathrm{a}$ & $4310 \mathrm{~b}$ \\
\hline $26-2$ & $29,1 \mathrm{~b}$ & $5705 \mathrm{a}$ & $27-1$ & $29,4 \mathrm{a}$ & 4849 a & $36-2$ & $33,7 \mathrm{a}$ & $4305 \mathrm{~b}$ \\
\hline $12-3$ & $34,1 \mathrm{a}$ & $5701 \mathrm{a}$ & $20-4$ & $22,4 \mathrm{~b}$ & $4841 \mathrm{a}$ & $26-3$ & $27,2 \mathrm{~b}$ & $4305 \mathrm{~b}$ \\
\hline $10-4$ & $29,8 \mathrm{a}$ & $5682 \mathrm{a}$ & $06-2$ & $29,0 \mathrm{~b}$ & 4829 a & $03-4$ & $26,9 \mathrm{~b}$ & $4299 \mathrm{~b}$ \\
\hline $02-1$ & $31,2 \mathrm{a}$ & $5634 \mathrm{a}$ & $12-4$ & $34,6 \mathrm{a}$ & $4825 \mathrm{a}$ & $18-1$ & $27,6 \mathrm{~b}$ & $4279 \mathrm{~b}$ \\
\hline $03-3$ & $27,2 \mathrm{~b}$ & 5607 a & $22-1$ & $31,6 \mathrm{a}$ & $4810 \mathrm{a}$ & $33-6$ & 30,9 a & $4273 \mathrm{~b}$ \\
\hline $22-2$ & $26,3 \mathrm{~b}$ & 5591 a & $30-4$ & $29,4 \mathrm{a}$ & $4807 \mathrm{a}$ & $28-2$ & $27,2 \mathrm{~b}$ & $4271 \mathrm{~b}$ \\
\hline $25-5$ & 38,6 a & $5587 \mathrm{a}$ & $22-5$ & $30,5 \mathrm{a}$ & $4784 \mathrm{a}$ & $08-1$ & $28,0 \mathrm{~b}$ & $4270 \mathrm{~b}$ \\
\hline $01-3$ & 33,6 a & $5560 \mathrm{a}$ & $21-2$ & $27,6 \mathrm{~b}$ & $4774 \mathrm{a}$ & $33-5$ & $26,2 \mathrm{~b}$ & $4256 \mathrm{~b}$ \\
\hline $10-2$ & $29,6 \mathrm{a}$ & $5553 \mathrm{a}$ & $20-2$ & $28,2 \mathrm{~b}$ & $4774 \mathrm{a}$ & $14-2$ & $23,9 \mathrm{~b}$ & $4251 \mathrm{~b}$ \\
\hline $26-1$ & $35,0 \mathrm{a}$ & $5525 \mathrm{a}$ & $05-1$ & $30,2 \mathrm{a}$ & 4756 a & $31-2$ & $27,5 \mathrm{~b}$ & $4239 \mathrm{~b}$ \\
\hline $05-3$ & $28,5 \mathrm{~b}$ & $5522 \mathrm{a}$ & $19-4$ & $28,9 \mathrm{~b}$ & $4753 \mathrm{a}$ & $19-1$ & $27,1 \mathrm{~b}$ & $4226 \mathrm{~b}$ \\
\hline $28-5$ & $31,3 \mathrm{a}$ & $5487 \mathrm{a}$ & $11-1$ & $31,2 \mathrm{a}$ & 4749 a & $29-1$ & $27,0 \mathrm{~b}$ & $4224 \mathrm{~b}$ \\
\hline $20-3$ & $25,6 \mathrm{~b}$ & $5476 \mathrm{a}$ & $22-3$ & $34,3 \mathrm{a}$ & $4720 \mathrm{a}$ & $30-1$ & 30,9 a & $4196 b$ \\
\hline $25-1$ & $33,5 \mathrm{a}$ & $5424 \mathrm{a}$ & $28-4$ & $31,4 \mathrm{a}$ & $4713 \mathrm{a}$ & $36-1$ & $32,8 \mathrm{a}$ & $4181 \mathrm{~b}$ \\
\hline $02-3$ & $28,7 \mathrm{~b}$ & $5420 \mathrm{a}$ & $21-4$ & $32,7 \mathrm{a}$ & $4670 \mathrm{a}$ & $01-1$ & 29,6 a & $4179 \mathrm{~b}$ \\
\hline $30-5$ & $27,7 \mathrm{~b}$ & $5404 \mathrm{a}$ & $15-6$ & $28,2 \mathrm{~b}$ & $4668 \mathrm{a}$ & $08-2$ & $26,7 \mathrm{~b}$ & $4158 \mathrm{~b}$ \\
\hline $15-3$ & $30,2 \mathrm{a}$ & 5399 a & $32-6$ & $29,8 \mathrm{a}$ & $4664 \mathrm{a}$ & $30-6$ & $28,5 \mathrm{~b}$ & $4153 b$ \\
\hline $02-4$ & $31,2 \mathrm{a}$ & $5390 \mathrm{a}$ & $34-4$ & $30,4 \mathrm{a}$ & $4653 \mathrm{a}$ & $17-2$ & $25,2 \mathrm{~b}$ & $4115 b$ \\
\hline $35-5$ & $27,3 \mathrm{~b}$ & 5329 a & $19-6$ & $31,0 \mathrm{a}$ & 4648 a & $35-2$ & $27,9 \mathrm{~b}$ & $4097 \mathrm{~b}$ \\
\hline $25-4$ & $36,6 \mathrm{a}$ & 5316 a & $13-1$ & $31,4 \mathrm{a}$ & 4648 a & $33-3$ & $25,9 \mathrm{~b}$ & $4071 \mathrm{~b}$ \\
\hline $27-3$ & $28,8 \mathrm{~b}$ & 5296 a & $10-6$ & $31,9 \mathrm{a}$ & $4644 \mathrm{a}$ & $30-2$ & $27,5 \mathrm{~b}$ & $4066 \mathrm{~b}$ \\
\hline $20-5$ & $26,1 \mathrm{~b}$ & $5295 \mathrm{a}$ & $11-2$ & $38,6 \mathrm{a}$ & $4643 \mathrm{a}$ & $21-6$ & $32,9 \mathrm{a}$ & $4058 \mathrm{~b}$ \\
\hline $25-6$ & $34,0 \mathrm{a}$ & $5291 \mathrm{a}$ & $02-6$ & $27,7 \mathrm{~b}$ & $4642 \mathrm{a}$ & $28-3$ & $24,4 \mathrm{~b}$ & $4038 \mathrm{~b}$ \\
\hline $22-4$ & $34,7 \mathrm{a}$ & 5286 a & $19-5$ & $32,1 \mathrm{a}$ & $4634 \mathrm{a}$ & $21-3$ & $29,0 \mathrm{~b}$ & $4036 \mathrm{~b}$ \\
\hline $05-2$ & $30,4 \mathrm{a}$ & 5283 a & $01-2$ & $30,1 \mathrm{a}$ & $4631 \mathrm{a}$ & $33-1$ & $26,8 \mathrm{~b}$ & $3975 \mathrm{~b}$ \\
\hline $10-5$ & $28,2 \mathrm{~b}$ & $5276 \mathrm{a}$ & $27-2$ & $28,6 \mathrm{~b}$ & $4622 \mathrm{a}$ & $27-4$ & $23,0 \mathrm{~b}$ & $3955 \mathrm{~b}$ \\
\hline $09-1$ & $28,0 \mathrm{~b}$ & $5247 \mathrm{a}$ & 03-1 & $29,5 \mathrm{a}$ & $4616 \mathrm{a}$ & $34-5$ & $31,9 \mathrm{a}$ & $3949 \mathrm{~b}$ \\
\hline $12-6$ & $34,4 \mathrm{a}$ & $5234 \mathrm{a}$ & $15-5$ & $29,3 \mathrm{a}$ & 4598 a & $18-2$ & $21,8 \mathrm{~b}$ & $3880 \mathrm{~b}$ \\
\hline $11-3$ & $34,1 \mathrm{a}$ & 5217 a & $03-6$ & $27,2 \mathrm{~b}$ & $4581 \mathrm{a}$ & $23-1$ & $28,0 \mathrm{~b}$ & $3857 \mathrm{~b}$ \\
\hline $34-6$ & $33,4 \mathrm{a}$ & $5185 \mathrm{a}$ & $27-5$ & $22,6 \mathrm{~b}$ & 4581 a & $28-1$ & $33,0 \mathrm{a}$ & $3823 \mathrm{~b}$ \\
\hline $15-1$ & 29,6 a & $5152 \mathrm{a}$ & $16-5$ & $29,5 \mathrm{a}$ & 4568 a & $35-4$ & $27,4 \mathrm{~b}$ & $3797 \mathrm{~b}$ \\
\hline $16-2$ & $31,0 \mathrm{a}$ & 5148 a & $32-5$ & $33,0 \mathrm{a}$ & $4567 \mathrm{a}$ & 04-1 & $27,9 \mathrm{~b}$ & $3749 \mathrm{~b}$ \\
\hline $15-4$ & $31,8 \mathrm{a}$ & $5119 \mathrm{a}$ & $16-1$ & $30,4 \mathrm{a}$ & $4555 \mathrm{a}$ & $08-3$ & $30,3 \mathrm{a}$ & $3709 \mathrm{~b}$ \\
\hline $17-1$ & $31,2 \mathrm{a}$ & $5104 \mathrm{a}$ & $03-2$ & $28,0 \mathrm{~b}$ & $4527 \mathrm{~b}$ & $33-2$ & $32,0 \mathrm{a}$ & $3681 \mathrm{~b}$ \\
\hline $14-1$ & 29,8 a & $5097 \mathrm{a}$ & $19-2$ & $27,9 \mathrm{~b}$ & $4520 \mathrm{~b}$ & $24-3$ & 27,6 b & $3659 \mathrm{~b}$ \\
\hline AS1522 & $26,0 \mathrm{~b}$ & 5095 a & $32-4$ & $36,2 \mathrm{a}$ & $4495 \mathrm{~b}$ & $09-2$ & $30,5 \mathrm{a}$ & $3602 \mathrm{~b}$ \\
\hline $35-3$ & $30,8 \mathrm{a}$ & $5086 \mathrm{a}$ & $30-3$ & $27,5 \mathrm{~b}$ & $4487 \mathrm{~b}$ & $33-4$ & $29,1 \mathrm{~b}$ & $3557 \mathrm{~b}$ \\
\hline $35-6$ & $25,7 \mathrm{~b}$ & 5085 a & $16-3$ & $30,6 \mathrm{a}$ & $4479 \mathrm{~b}$ & $29-2$ & $26,6 \mathrm{~b}$ & $3542 \mathrm{~b}$ \\
\hline $10-3$ & $31,2 \mathrm{a}$ & $5023 \mathrm{a}$ & $28-6$ & $26,9 \mathrm{~b}$ & $4443 \mathrm{~b}$ & $32-3$ & $31,4 \mathrm{a}$ & $3510 \mathrm{~b}$ \\
\hline
\end{tabular}


Continuação Tabela 5

\begin{tabular}{ccccccccc}
\hline $16-4$ & $28,7 \mathrm{~b}$ & $5016 \mathrm{a}$ & $25-3$ & $35,3 \mathrm{a}$ & $4411 \mathrm{~b}$ & $06-3$ & $26,6 \mathrm{~b}$ & $3442 \mathrm{~b}$ \\
$25-2$ & $33,9 \mathrm{a}$ & $5011 \mathrm{a}$ & $01-4$ & $30,1 \mathrm{a}$ & $4400 \mathrm{~b}$ & $32-1$ & $33,1 \mathrm{a}$ & $3421 \mathrm{~b}$ \\
$15-2$ & $30,9 \mathrm{a}$ & $5008 \mathrm{a}$ & $07-1$ & $23,9 \mathrm{~b}$ & $4396 \mathrm{~b}$ & $31-3$ & $29,6 \mathrm{a}$ & $3416 \mathrm{~b}$ \\
$35-1$ & $29,5 \mathrm{a}$ & $4994 \mathrm{a}$ & $01-5$ & $30,3 \mathrm{a}$ & $4393 \mathrm{~b}$ & $02-2$ & $29,6 \mathrm{a}$ & $3354 \mathrm{~b}$ \\
$21-5$ & $27,1 \mathrm{~b}$ & $4970 \mathrm{a}$ & $12-2$ & $35,2 \mathrm{a}$ & $4388 \mathrm{~b}$ & $23-2$ & $26,7 \mathrm{~b}$ & $3269 \mathrm{~b}$ \\
$03-5$ & $26,9 \mathrm{~b}$ & $4962 \mathrm{a}$ & $20-1$ & $25,8 \mathrm{~b}$ & $4383 \mathrm{~b}$ & $24-2$ & $28,8 \mathrm{~b}$ & $3161 \mathrm{~b}$ \\
$10-1$ & $31,1 \mathrm{a}$ & $4950 \mathrm{a}$ & $34-3$ & $27,4 \mathrm{~b}$ & $4381 \mathrm{~b}$ & $07-3$ & $19,3 \mathrm{~b}$ & $3143 \mathrm{~b}$ \\
$31-1$ & $29,7 \mathrm{a}$ & $4950 \mathrm{a}$ & $19-3$ & $31,6 \mathrm{a}$ & $4375 \mathrm{~b}$ & $18-4$ & $25,3 \mathrm{~b}$ & $3122 \mathrm{~b}$ \\
$34-2$ & $29,9 \mathrm{a}$ & $4925 \mathrm{a}$ & BR106 & $34,2 \mathrm{a}$ & $4364 \mathrm{~b}$ & $32-2$ & $30,0 \mathrm{a}$ & $3021 \mathrm{~b}$ \\
$09-3$ & $32,0 \mathrm{a}$ & $4885 \mathrm{a}$ & $20-6$ & $26,5 \mathrm{~b}$ & $4345 \mathrm{~b}$ & $18-5$ & $28,2 \mathrm{~b}$ & $2964 \mathrm{~b}$ \\
$01-6$ & $32,0 \mathrm{a}$ & $4878 \mathrm{a}$ & $24-1$ & $28,4 \mathrm{~b}$ & $4337 \mathrm{~b}$ & $18-3$ & $19,5 \mathrm{~b}$ & $2903 \mathrm{~b}$ \\
$06-1$ & $25,5 \mathrm{~b}$ & $4876 \mathrm{a}$ & $18-6$ & $22,1 \mathrm{~b}$ & $4334 \mathrm{~b}$ & Média & 29,4 & 4596,6 \\
$34-1$ & $27,5 \mathrm{~b}$ & $4875 \mathrm{a}$ & $16-6$ & $27,6 \mathrm{~b}$ & $4316 \mathrm{~b}$ & C.V. $(\%)$ & 14,8 & 20,9 \\
\hline
\end{tabular}

Médias seguidas de mesma letra não diferem entre si a 5\% de significância pelo teste Scott e Knott

O híbrido comercial AS1522 apresentou $5095 \mathrm{~kg} \mathrm{ha}^{-}$ ${ }^{1}$ de produtividade, fazendo parte do grupo mais produtivo e a variedade BR106, com $4364 \mathrm{~kg} \mathrm{ha}^{-1}$, está inserida no grupo de menor produtividade. Esta diferença se atribui ao fato de o híbrido apresentar maior heterose em relação à variedade, consequentemente refletindo em sua maior produtividade.

Mesmo não diferindo estatisticamente, 37 genótipos apresentaram produtividades superiores ao híbrido testemunha, com destaque para o genótipo 02-5, com a maior produtividade (6726 kg ha-1), sendo $25 \%$ mais produtivo que o híbrido comercial (1631 kg ha-1) mais produtivo. Esta diferença pode estar relacionada ao fato de que o programa de melhoramento que gerou o híbrido comercial foi desenvolvido em condições climáticas diferente das encontradas no Tocantins. Inúmeros os relatos dos ganhos em se desenvolver genótipos específicos nas condições edafoclimáticas onde se pretende cultivar tal material (MAJEROWICZ et al., 2002; BANZIGER et al., 1997; LAFFITTE; EDMEADES, 1994).

O uso de cultivares apropriadas pode explicar até $50 \%$ da variação em produtividade. Dessa forma, melhores cultivares são interessantes pois não alteram o sistema produtivo do agricultor e não implicam em grandes gastos adicionais (CÂMARA, 2007).

Variedades de polinização aberta, comparadas a híbridos, têm menor custo de sementes, podem ser multiplicadas pelo próprio produtor, não exigem alta tecnologia de produção e têm a capacidade de se adaptarem a diversas condições ambientais, entre outros aspectos que favorecem a sua adoção (CÂMARA, 2007).

\section{Conclusões}

1. Os genótipos $01-5 ; 02-1 ; 02-2 ; 02-3 ; 02-4 ; 10-5 ; 25-1 ; 32-1$ e 34-4 são os que reúnem o conjunto de características mais favoráveis para o desenvolvimento de genótipos comerciais voltados para o consumo in natura;

2. Os genótipos do programa de Melhoramento de Milho da UFT possuem potencial produtivo e podem ser utilizados para o desenvolvimento de cultivares voltadas para uso nas condições edafoclimáticas do Tocantins.

\section{Agradecimentos}

À CAPES pela concessão de bolsa PNPD e bolsa de mestrado ao primeiro autor. Ao Conselho Nacional de Desenvolvimento Ciêntífico e Tecnológico (CNPq) pelo financiamento do projeto.

\section{Referências}

ARAUJO, P. M.; NASS, L. L. Caracterização e avaliação de populações de milho crioulo. Scientia Agricola, v. 59, n. 03, p. 589-593, jul./set. 2002.

ALBUQUERQUE, C. J. B. et al. Desempenho de híbridos experimentais e comerciais de milho para produção de milho verde. Ciência e Agrotecnológica, v. 32, n. 03, 2008.

BANZIGER, M., F. J.; BEARN, I.; LAFFITTE, H. R. Efficiency of high nitrogen selection environments for improving maize for low nitrogen target environments. Crop Science, v. 37, n. 04, p. 1103-1109, 1997. 
CÂMARA, T. M. M. Rendimento de grãos verdes e secos de cultivares de milho. Revista Ceres, v. 54, n. 311, p. 87-92. 2007.

CANCELLIER, L. L. et al. Eficiência no uso de nitrogênio e correlação fenotípica em populações tropicais de milho no Tocantins. Revista Ciência Agronômica, v. 42, n. 01, p. 139-148, 2011.

CARNEIRO, V. Debulha, classificação em tamanho e armazenamento na qualidade de sementes de milho-pipoca. 2002. 40 f. Dissertação (Mestrado em Fitotecnia) - Universidade Federal de Viçosa, Viçosa.

CONAB - (Companhia Nacional do Abastecimento). Série histórica. Comparativo de área, produção e produtividade. Disponível em: <http://www.conab.gov.br/conabweb/index. php?PAG=131>. Acesso em: 31 de mar. 2010.

CRUZ, J. C.; PEREIRA FILHO, I. A. Cultivares de Milho disponíveis no mercado de sementes do Brasil para a safra 2006/07. 2007. Disponível em < http://www.cnpms.embrapa.br/ milho/cultivares/index.php>. Acesso em: 21 de jan. 2007.

DURÃES, F. O. M. et al. Fenotipagem associada a tolerância a seca em milho para uso em melhoramento, estudos genômicos e seleção assistida por marcadores. Sete Lagoas: Embrapa-CNPMS. 2004. 18p. (Circular Técnica 39).

FANCELLI, A. L.; DOURADO-NETO, D. Produção de milho. Guaíba: Agropecuária, 2000. 360 p.

GUIMARÃES, C. M.; STONE, L. F.; NEVES, P. de C. F. Eficiência produtiva de cultivares de arroz com divergência fenotípica. Revista brasileira de engenharia agrícola e ambiental, v. 12, n. 05, p 465-470, 2008.

LAFFITTE, H. R.; EDMEADES, G. O. Improvement for tolerance to low soil nitrogen in tropical maize. II. Grain yield, biomass production, and $\mathrm{N}$ accumulation. Field Crop Research, v. 39, n. 01, p. 15-25, 1994.

MAJEROWICZ, N.; et al. Estudo da eficiência de uso do nitrogênio em variedades locais e melhoradas de milho. Revista
Brasileira de Botânica, v. 25, n. 02, p. 129-136, 2002.

MATSUSHIMA, S. Crop science in rice: theory of yield determination and its application. Tokyo: Fuji, 1970. 379 p.

MIRANDA, G. V. et al. Potencial de melhoramento e divergência genética de cultivares de milho-pipoca. Pesquisa Agropecuária Brasileira, v. 38, n. 06, p. 681-688, 2003.

MORAES. A. R. A. A cultura do milho verde. Disponível em: $<$ http://www.iac.sp.gov.br/tecnologias/milhoverde/milhoverde. htm>, acesso em 06 de abr. 2010.

OLIVEIRA, F. A. et al. Crescimento do milho adubado com nitrogênio e fósforo em um Latossolo Amarelo. Revista Brasileira de Ciências Agrárias, v. 04, n. 03, p. 238-244, 2009.

OLIVEIRA, J. P. et al. Qualidade física do grão em populações de milho de alta qualidade protéica e seus cruzamentos. Pesquisa Agropecuária Tropical, v. 37, n. 04, p. 233-241, 2007.

OLIVEIRA JÚNIOR, L. F. G. et al. Seleção de genótipos de milho mais promissores para o consumo in natura. Ciência de Tecnologia de Alimentos, v. 26, n. 01, p. 159-165, 2006.

PEREIRA FILHO, I. A.; CRUZ, J. C. Cultivares de Milho para o Consumo Verde. Sete Lagoas: Embrapa-CNPMS, 2002. 7 p. (Circular Técnica n. 15).

PEREIRA FILHO, I. A.; CRUZ, J. C.; GAMA, E. E. G. Cultivares para o consumo verde. In: PEREIRA FILHO, I. A (Ed.). O cultivo do milho verde. 2003. Cap. 1, p. 17-30.

PINHO, L.; et al. Qualidade de milho verde cultivado em sistemas de produção orgânico e convencional. Revista Brasileira de Milho e Sorgo, v. 07, n. 03, p. 279-290, 2008.

RODRIGUES, F.; et al. Capacidade de combinação entre linhagens de milho visando à produção de milho verde. Bragantia, v. 68, n. 01, p. 75-84, 2009.

SANTOS, I. C. et al. Comportamento de cultivares de milho produzidos organicamente e correlações entre características das espigas colhidas no estádio verde. Revista Brasileira de Milho e Sorgo, v. 04, n. 01, p. 45-53, 2005. 